\title{
KORELASI ANTARA SELF-REGULATED LEARNING DENGAN KEMAMPUAN PEMAHAMAN Matematis MaHaSisWa
}

\author{
Angra Meta Ruswana ${ }^{1^{*}}$ dan Lala Nailah Zamnah ${ }^{2}$ \\ 1Jurusan Pendidikan Matematika, Universitas Galuh \\ Jl. R.E. Martadinata No. 150, Ciamis, Mekarjaya, Jawa Barat, Indonesia \\ angra.meta@gmail.com \\ ${ }^{2}$ Jurusan Pendidikan Matematika, Universitas Galuh \\ Jl. R.E. Martadinata No. 150, Ciamis, Mekarjaya, Jawa Barat, Indonesia \\ nailah_lala@yahoo.co.id
}

Artikel diterima: 1 Agustus 2018, direvisi: 15 September 2018, diterbitkan: 30 September 2018

\begin{abstract}
Abstrak
Penelitian ini dilatarbelakangi oleh kemampuan pemahaman matematis mahasiswa yang masih belum maksimal dan juga mahasiswa belum bisa mengatur diri dalam belajar terutama ketika menghadapi tugas sehingga berpengaruh terhadap self-regulated learning mahasiswa. Tujuan dari penelitian yang dilakukan adalah untuk menelaah dan mendeskripsikan korelasi antara selfregulated learning dengan kemampuan pemahaman matematis mahasiswa. Penelitian dilaksanakan di Program Studi Pendidikan Matematika Universitas Galuh pada mahasiswa tingkat I Tahun Akademik 2017/2018. Data hasil penelitian diperoleh dari instrumen tes kemampuan pemahaman matematis dan angket skala self-regulated learning. Analisis data yang digunakan adalah analisis korelasi dengan menggunakan korelasi product moment. Berdasarkan hasil penelitian, pengolahan data, analisis data dan pengujian hipotesis diperoleh kesimpulan bahwa terdapat korelasi antara self-regulated learning dengan kemampuan pemahaman matematis mahasiswa.

Kata Kunci: kemampuan pemahaman matematis, self-regulated learning, korelasi.

Abstract (Correlation between Self-Regulated Learning and Students' Mathematical Understanding Ability)

This research was conducted based on the consideration of low mathematical understanding ability and their awareness in accomplishing their assignments. These obstacles influence to their self-regualted learning. The aim of this study was to investigated and to decribed the correlation between self-regulated learning with mathematical understanding ability. This study was conducted in mathematics eduaction program in Galuh University. The population is the first year of students in academic year 2017/2018. The data was obtained from test and questionnaire deals with self-regulated learning. The research design was used correlation with the Pearson's product moment analysis. The result was showed that there is positive correlation between selfregulated with mathematical understanding ability.

Keyword: Mathematical Understanding Ability, self-regulated learning, and correlation.
\end{abstract}




\section{Pendahuluan}

Matematika merupakan ilmu universal yang mendasari perkembangan teknologi modern, mempunyai peran penting dalam berbagai disiplin dan memajukan daya pikir manusia (Depdiknas, 2006). Matematika perlu dipahami oleh semua lapisan masyarakat terutama siswa sekolah formal, sehingga matematika merupakan salah satu ilmu yang diajarkan dari jenjang Sekolah Dasar (SD) hingga Perguruan Tinggi (PT). Dalam Standar Isi (SI) kurikulum 2006 dinyatakan bahwa tujuan mata pelajaran matematika di sekolah adalah agar siswa mampu memahami konsep matematika, menggunakan penalaran, memecahkan masalah, mengkomunikasikan gagasan, memiliki sikap menghargai kegunaan matematika dalam kehidupan (Wardhani, 2010). Dari penjelasan tersebut, pemahaman merupakan hal yang penting dan merupakan hal dasar yang harus dimiliki seseorang dalam mempelajari matematika.

Keberagaman latar belakang pendidikan pada mahasiswa Pendidikan Matematika FKIP Universitas Galuh menjadi salah satu faktor penghambat mahasiswa dalam mengikuti perkuliahan. Pada umumnya mahasiswa yang kesulitan belajar matematika saat di SD, SMP dan SMA berdampak pada rendahnya sikap dan kemampuan pemahaman matematis pada perkuliahan, sehingga masih memungkinkan adanya anggapan negatif mahasiswa terhadap matematika, dalam hal ini dalam mata kuliah Pegantar Dasar Matematika.

Berdasarkan pengamatan peneliti selama mengajar mahasiswa Pendidikan Matematika di FKIP Universitas Galuh dan berdasarkan wawancara dengan beberapa mahasiswa, mereka merasa kurang memiliki kemampuan pemahaman matematis dan masih belum bisa mengatur diri dalam belajar terutama ketika menghadapi tugas.

Mata kuliah Pengantar Dasar Matematika dalam struktur kurikulum Jurusan S1 Pendidikan Matematika FKIP Universitas Galuh diberikan kepada mahasiswa semester ke-2. Mata kuliah ini menjadi sangat penting karena memberikan manfaat dalam membekali mahasiswa pengetahuan dan keterampilan dasar matematika. Materi pada perkuliahan Pengantar Dasar Matematika ini sebenarnya sudah mahasiswa peroleh ketika di jenjang pendidikan sebelumnya sehingga nilai akhir atau perolehan nilai yang diperoleh mahasiswa haruslah memuaskan.

Berdasarkan hasil analisis terhadap lembar jawaban soal ujian mahasiswa, masih terdapat kecenderungan jawaban benar untuk soal tentang konsep dasar, namun tidak demikian untuk soal penerapannya. Berdasarkan fakta yang telah dikemukakan, hal ini menunjukkan bahwa kemampuan pemahaman matematis mahasiswa masih belum maksimal. Kemampuan pemahaman matematis yang belum maksimal juga 
berdampak pada soft skill mahasiswa yaitu self-regulated learning.

Untuk mengatasinya, maka dilakukan perubahan dalam proses belajar mengajar. Perubahan yang dilakukan berupa penggunaan model pembelajaran, dimana model pembelajaran yang digunakan adalah model pembelajaran Self-Directed Learning (SDL). Model pembelajaran SelfDirected Learning (SDL) atau pembelajaran mandiri adalah proses belajar yang dilakukan atas inisiatif sendiri.

Berdasarkan uraian yang telah dikemukakan, maka rumusan masalah dalam penelitian ini adalah adakah korelasi antara self-regulated learning (SRL) dengan kemampuan pemahaman matematis mahasiswa. Sedangkan tujuan dilakukan penelitian adalah untuk menelaah dan mendeskripsikan korelasi antara SRL dengan kemampuan pemahaman matematis mahasiswa.

Gibbons (2002) mengemukakan bahwa self-directed learning (SDL) merupakan suatu keterampilan dimana seseorang mampu untuk menentukan sendiri dan memilih tujuan yang ingin dicapainya, merencanakan strategi yang akan dilakukan, berusaha untuk memecahkan masalah, memanajemen dirinya, serta mengevaluasi pemikiran dan kinerja yang telah dilakukan. Keterampilan ini akan meningkatkan pengetahuan, keahlian, dan prestasi individu. Self-directed learning (SDL) artinya belajar yang bebas menentukan arah rencana, sumber, dan keputusan untuk mencapai tujuan akademik. Proses SDL mengubah peran Mosharafa: Jurnal Pendidikan Matematika Volume 7, Nomor 3, September 2018 Copyright $\odot 2018$ Mosharafa: Jurnal Pendidikan Matematika pembelajar atau instruktur menjadi fasilitator atau perancang proses belajar (Yamin, 2013).

Secara garis besar, model SDL dibagi menjadi tiga tahapan yaitu planning, monitoring dan evaluating (Song \& Hill, 2007). Tahapan ini diawali dengan mahasiswa merencanakan aktivitas untuk belajar, merencanakan komponen belajar yang diinginkan serta menentukan target belajar yang ingin dicapai kemudian mengamati dan mengobservasi pembelajaran mereka. Sedangkan menurut Hiemstra (dalam Richard, 2007), langkah-langkah SDL dibagi menjadi enam yaitu preplanning, menciptakan lingkungan belajar yang positif, mengembangkan rencana pembelajaran, mengidentifikasi aktivitas pembelajaran yang sesuai, melaksanakan kegiatan pembelajaran dan mengevaluasi hasil belajar individu.

Kemampuan pemahaman ini merupakan hal yang sangat fundamental, karena dengan pemahaman akan dapat mencapai pengetahuan prosedur (AlSyiam dan Sundayana, 2014). Qohar (Muna dan Afriansyah, 2016) menyatakan bahwa kemampuan pemahaman matematis adalah kemampuan mengklasifikasikan obyek-obyek matematika, menginterpretasikan gagasan atau konsep, menemukan contoh dari sebuah konsep, memberikan contoh dan bukan contoh dari sebuah konsep dan menyatakan kembali konsep matematika dengan bahasa sendiri. Luritawaty (2018) mengatakan bahwa masih rendahnya 
kemampuan pemahaman matematis pada mahasiswa.

Kemampuan pemahaman matematis adalah salah satu tujuan penting dalam pembelajaran, memberikan pengertian bahwa materi-materi yang diajarkan kepada mahasiswa bukan hanya sebagai hafalan, namun lebih dari itu dengan pemahaman siswa dapat lebih mengerti akan konsep materi pelajaran itu sendiri. Pemahaman matematis merupakan salah satu tujuan yang diharapkan bisa tercapai dengan baik oleh mahasiswa.

Anderson (dalam Minani dkk, 2016), menyatakan understand is defined as constructing the meaning of instructional messages, including oral, written, and graphic communication. Menurut pendapat tersebut, mahasiswa harus mampu mengkonstruksi makna dari pesan-pesan pengajaran seperti komunikasi lisan, tulisan, dan grafik agar mereka bisa dikatakan memahami sesuatu.

Pemahaman akan sebuah konsep ilmu pengetahuan yang sedang dipelajari memiliki peranan yang sangat penting. Mahasiswa akan berkembang ke jenjang kognitif yang lebih tinggi jika ia memiliki pemahaman konsep yang baik. Jika pemahaman konsep dikuasai dengan baik, maka mahasiswa akan mampu menghubungkan atau mengaitkan sebuah konsep yang satu dengan yang lainnya. Selain itu, konsep tersebut dapat digunakan untuk memecahkan permasalahan dari mulai yang sederhana hingga ke permasalahan yang lebih 384 kompleks. Tingkat pemahaman seseorang terhadap suatu konsep dapat dilihat dari jenis-jenis pemahaman yang dimilikinya.

Kemampuan pemahaman matematis yang digunakan adalah kemampuan pemahaman matematis menurut Polya (Sumarmo, 2010 ). Polya (Sumarmo, $2010^{\text {b }}$ menyatakan empat tingkat pemahaman matematis, yaitu pemahaman mekanikal, pemahaman induktif, pemahaman rasional dan pemahaman intuitif. Pemahaman mekanikal berarti dapat mengingat dan menerapkan hukum secara benar. Pemahaman induktif berarti menerapkan hukum ke dalam kasus sederhana dan meyakini bahwa hukum bisa diberlakukan untuk kasus yang serupa. Pemahaman rasional berarti dapat membuktikan kebenaran dari suatu hukum. Pemahaman intuitif berarti meyakini hukum tanpa keragu-raguan dan memberikan prediksi dengan bukti kebenarannya.

Pintrict \& Groot (1990) memberikan istilah self-regulated dalam belajar dengan istilah SRL. Kemandirian belajar atau SRL adalah kemampuan seseorang yang memiliki pengetahuan mengenai strategi belajar efektif dan mengetahui bagaimana serta kapan menggunakan pengetahuan tersebut sehingga siswa mampu mengatur diri dalam belajar. Self-regulated learning menempatkan pentingnya kemampuan seseorang untuk mengatur dan mengendalikan diri sendiri, terutama bila menghadapi tugas. Hal ini sejalan dengan yang diungkapkan Zimmerman \& Pons (1990) bahwa seorang siswa yang 
mempunyai kemandirian dalam belajar memperlihatkan kemampuannya dalam mengendalikan proses belajar.

Pintrich (dalam Mukhid, 2008), prosesproses regulatory dikelompokkan menjadi empat fase yaitu perencanaan, monitoring diri, kontrol dan evaluasi, dimana dalam setiap fase aktifitas self-regulated tersusun dalam empat area yaitu kognitif, motivasional/afektif, behavioral dan kontekstual. Berdasarkan uraian yang telah dikemukakan, maka SRL yang digunakan dalam penelitian ini adalah (1) inisiatif belajar, (2) mendiagnosa kebutuhan belajar, (3) menetapkan tujuan belajar, (4) memonitor, mengatur dan mengontrol belajar, (5) memandang kesulitan sebagai tantangan, (6) memanfaatkan dan mencari sumber yang relevan, (7) memilih dan menetapkan strategi belajar yang tepat, (8) mengevaluasi proses dan hasil belajar, (9) konsep diri.

\section{Metode}

Penelitian ini akan dilaksanakan di Program Studi Pendidikan Matematika Universitas Galuh pada mahasiswa tingkat I semester 2 Tahun Akademik 2017/2018 pada Mata Kuliah Pengantar Dasar Matematika. Penelitian melibatkan dua kelas, kelas pertama memperoleh pembelajaran SDL dan kelas kedua memperoleh pembelajaran secara konvensional.

Instrumen yang digunakan dalam penelitian ini adalah tes dan non-tes.

Mosharafa: Jumal Pendidikan Matematika

Volume 7, Nomor 3, September 2018

Copyright @ 2018 Mosharafa: Jurnal Pendidikan Matematika
Instrumen tes berupa soal-soal kemampuan pemahaman matematis yang berupa soal uraian (essay), yang dibuat berdasarkan indikator kemampuan pemahaman matematis. Sedangkan instrumen non-tes adalah angket skala SRL, dibuat berdasarkan indikator SRL. Soal tes kemampuan pemahaman matematis yang digunakan terlebih dahulu sudah diujicobakan ke mahasiswa yang sudah mengikuti perkuliahan Pengantar Dasar Matematika. Soal tes yang diujicobakan, kemudian dianalisis dan dari hasil analisis dipilih 4 soal yang memuat semua indikator kemampuan pemahaman matematis yang akan diteliti dan memenuhi unsur validitas, reliabilitas, indeks kesukaran dan daya beda.

Instrumen tes yang dibuat adalah tes tertulis kemampuan pemahaman matematis berdasarkan tingkat pemahaman matematis menurut polya, yaitu pemahaman mekanikal, pemahaman induktif, pemahaman rasional, dan pemahaman intuitif.

Instrumen SRL dimodifikasi dari skala SRL yang disusun oleh Sumarmo (2004 $\left.{ }^{\mathrm{a}}\right)$. Tujuan memodifikasinya adalah untuk menyesuaikan dengan karakteristik pembelajaran.

Teknik pengumpulan data kuantitatif dilakukan dengan cara studi lapangan atau langsung pada saat kegiatan pembelajaran dilaksanakan. Teknik kuantitatif terdiri dari teknik tes dan non-tes. Teknik tes dalam penelitian ini untuk mengukur peningkatan kemampuan pemahaman matematis mahasiswa yang berupa soal 385 
uraian (essay) dan teknik non-tes dalam penelitian ini untuk mengukur peningkatan SRL.

Teknik analisis data yang digunakan dalam penelitian ini adalah uji korelasi menggunakan uji korelasi product moment. Uji Korelasi antara SRL dengan kemampuan pemahaman matematis mahasiswa. Selanjutnya untuk melihat korelasi antara kemampuan pemahaman matematis dan SRL mahasiswa dengan menggunakan SPSS 23.0 for Windows.

\section{Hasil dan Pembahasan}

Analisis statistik yang digunakan untuk mencari korelasi antara SRL dengan kemampuan pemahaman matematis mahasiswa adalah korelasi product moment. Data yang berasal dari kemampuan pemahaman matematis berupa data interval dan data yang berasal dari SRL erupa data ordinal. Karena salah satu data berupa data ordinal, maka analisis data yang digunakan adalah uji Spearman Rank. Hasil analisisnya disajikan dalam tabel berikut:

Tabel 1.

Uji Korelasi

\begin{tabular}{|c|c|c|c|}
\hline \multicolumn{2}{|c|}{ Korelasi } & \multirow{2}{*}{$\begin{array}{c}\text { Kemampuan } \\
\text { Pemahaman } \\
\text { Matematis } \\
1,000\end{array}$} & \multirow{2}{*}{$\begin{array}{c}\begin{array}{c}\text { Self- } \\
\text { Regulated } \\
\text { Learning }\end{array} \\
0,649\end{array}$} \\
\hline $\begin{array}{l}\text { Kema } \\
\text { mpuan }\end{array}$ & $\begin{array}{l}\text { Koefisien } \\
\text { Korelasi }\end{array}$ & & \\
\hline Pemah & Signifikansi & - & 0,000 \\
\hline $\begin{array}{l}\text { aman } \\
\text { Matem } \\
\text { atis }\end{array}$ & $\mathrm{N}$ & 33 & 33 \\
\hline $\begin{array}{l}\text { Self- } \\
\text { Regula }\end{array}$ & $\begin{array}{l}\text { Koefisien } \\
\text { Korelasi }\end{array}$ & 0,649 & 1,000 \\
\hline ted & Signifikansi & 0,000 & - \\
\hline $\begin{array}{l}\text { Learnin } \\
g\end{array}$ & $\mathrm{~N}$ & 33 & 33 \\
\hline
\end{tabular}

Berdasarkan Tabel 1, diperoleh nilai signifikansi sebesar 0,000 kurang dari 0,05, maka dapat disimpulkan bahwa hipotesis nol yang menyatakan tidak terdapat korelasi antara SRL dengan kemampuan pemahaman matematis mahasiswa ditolak.

Hal ini berarti terdapat korelasi antara SRL dengan kemampuan pemahaman matematis mahasiswa. Nilai koefisien korelasinya adalah 0,649, artinya korelasi antara SRL dengan kemampuan pemahaman matematis mahasiswa berada pada kategori kuat.

Nilai korelasi positif ini menunjukkan bahwa terdapat hubungan yang saling mempengaruhi antara SRL dan kemampuan pemahaman matematis mahasiswa. Artinya apabila SRL mahasiswa meningkat, maka kemampuan pemahaman matematisnya pun akan meningkat. Begitu juga sebaliknya, apabila SRL mahasiswa menurun, maka kemampuan pemahaman matematisnya pun akan menurun.

Hal ini didukung oleh studi temuan Hargis (Sumarmo, 2004 ${ }^{\mathrm{a}}$ ) bahwa individu yang memiliki SRL yang tinggi cenderung belajar lebih baik, mampu memantau, mengevaluasi, dan mengatur belajarnya secara efektif, menghemat waktu dalam menyelesaikan tugasnya, mengatur belajar dan waktu secara efisien, dan memperoleh skor yang tinggi dalam sains. 


\section{Penutup}

Berdasarkan uji korelasi menggunakan uji korelasi product moment, diperoleh kesimpulan bahwa terdapat korelasi antara SRL dengan kemampuan pemahaman matematis mahasiswa. Uji korelasi yang dilakukan berada pada kategori korelasi kuat artinya SRL dengan kemampuan pemahaman matematis mahasiswa saling memperngaruhi.

Berdasarkan penelitian yang telah dilakukan, maka peneliti memberikan saran agar dilakukan penelitian lebih lanjut pada kemampuan matematis lain dan soft skill lain dalam berbagai jenjang pendidikan. Agar nantinya bisa terlihat pada bagian kemampuan mana yang bisa memberikan kontribusi besar dalam bidang penelitian terutama bidang pendidikan matematika.

\section{UCAPAN TERIMA KaSIH}

Peneliti ucapkan terimakasih kepada Kementrian Riset, Teknologi dan Pendidikan Tinggi karena telah memberikan kesempatan untuk terlibat dalam skema Penelitian Dosen pemula (PDP), Universitas Galuh yang telah memberikan kesempatan dan fasilitas kepada peneliti selama melakukan penelitian serta mahasiswa Program Studi Pendidikan Matematika Universitas Galuh pada mahasiswa tingkat II Tahun Akademik 2017/2018 pada Mata Kuliah Pengantar Dasar Matematika atas kerjasamanya selama penelitian berlangsung .

\section{Daftar Pustaka}

Al-Syiam, E dan Sundayana, R. (2014). Perbandingan Kemampuaan

Pemahaman Matematika antara Siswa yang Mendapatkan Pembelajaran Contextual Teaching and Learning (CTL) dan Metakognitif. Mosharafa: Jurnal Pendidikan Matematika. Vol. 3. No. 1. 55-67.

Departemen Pendidikan Nasional. (2006). Kurikulum Tingkat Satuan Pendidikan. Jakarta: Pusat Kurikulum Balitbang Depdiknas.

Gibbons, M. (2002). The Self-Directed Learning Handbook: Challenging Adolescent Student to Excel. San Francisco: John Wiley \& Sons, Inc.

Luritawati, I. P. (2018). Pembelajaran Take and Give dalam Upaya Mengembangkan Kemampuan Pemahaman Konsep Matematis. Mosharafa: Jurnal Pendidikan Matematika. 7(2). 179-188.

Minani, A, et. Al. (2016). Mathematical Understanding and Representation Ability of Public Junior High School in North Sumatra. Journal on Mathematics Education. Vol 7. No 1. 45-58.

Mukhid, A. (2008). Strategi Self-Regulated Learning. Jurnal Tadris, 3(2). 222-239. Muna, D. N dan Afiansyah, E. A. (2016). Peningkatan Kemampuan Pemahaman Matematis Siswa melalui Pembelajaran Kooperatif Teknik Kancing Gamerincing dan Number Head Together. Mosharafa: Jurnal 
Pendidikan Matematika. Vol. 5. No. 2. 169-177.

Pintrich, P.R \& Groot, De. (1990). Motivational and Self-Regulated Learning Component of Classroom Academic Performance. Journal of Educational Psychology. 82 (1). 33-40.

Richard, B. R. (2007). Self-Directed Learning: A Process Perspective. International Journal of Self-Directed Learning, 4(1): 53-64.

Song, L \& Hill, J. R. (2007). A Conceptual Model for Understanding SelfDirected Learning in Online Environments. Journal of Interactive Online Learning, 6(1): 27-42.

Sugiyono. (2013). Metode Penelitian Pendidikan (Pendekatan Kuantitatif, Kualitatif dan R\&D). Bandung: Alfabeta.

Sumarmo, U. $\left(2004^{\mathrm{a}}\right)$. Kemandirian Belajar, Apa, Mengapa dan Bagaimana Dikembangkan pada Peserta Didik. Laporan Penelitian UPI. Tidak diterbitkan.

Sumarmo, U. $\left(2010^{\mathrm{b}}\right)$. Pendidikan Karakter, Berpikir dan Disposisi Logis, Kritis, dan Kreatif dalam Pembelajaran Matematika. Makalah pada perkuliahan Evaluasi Matematika 2011 SPS UPI: Tidak Diterbitkan.

Yamin, M. (2013). Strategi dan Metode dalam Model Pembelajaran. Jakarta: Referensi (GP Press Group).

Zimmerman, B. J dan Pons, M. M. (1990). Student Differences in Self-Regulated Learning: Relating Grade, Sex, and Giftedness to Self-Efficacy and 388
Strategy Use. Journal of Educational Psychology, 82(1).51-59. 